\title{
O LUGAR DO GRUPO ESCOLAR CÉSAR BASTOS NO CONTEXTO HISTÓRICO-EDUCACIONAL DE RIO VERDE (1947-1961) ${ }^{1}$
}

\author{
Maria Helena Cicci Romero \\ Maria Aparecida Alves Silva \\ Kênia Guimarães Furquim Camargo \\ Juscimar Maria de Paula
}

\section{RESUMO}

O presente estudo tem como objetivo principal analisar a gênese do Grupo Escolar César Bastos e sua finalidade como instituição escolar no contexto histórico da cidade de Rio Verde no período em apreço. Trata-se de uma pesquisa qualitativa, de cunho documental e tem como fontes principais a ata de fundação do Grupo Escolar, ofícios, livros de ponto e entrevistas semiestruturadas com pessoas que participaram da construção histórica da instituição escolar. Em linhas gerais, através dessa investigação, foi possível observar que questões políticas permearam o processo de criação do Grupo Escolar César Bastos, o que não impediu sua contribuição significativa para o declínio do índice de analfabetismo no município.

Palavras-chave: Grupo escolar. Rio Verde. Ensino público.

\section{TITLE}

\section{ABSTRACT}

The present study aims at analyzing the genesis of the Elementary School Cesar Bastos and its purpose as a school institution in the historical context of the city of Rio Verde in the period. This is a qualitative research, the documentary character and its main sources the minutes of the founding of the primary school, crafts, books point and semi-structured interviews with people who participated in the historic building of the school. In general, through this research, it was observed that political issues involved in the process of creating the School Group Cesar Bastos, which did not prevent his significant contribution to the decline of illiteracy in the county.

Keywords: Group school. Rio Verde. Public Education.

\section{Introdução}

Este trabalho - situado no âmbito da história e historiografia da educação brasileira - apresenta resultados parciais da investigação científica iniciada em 2012, sobre o processo de gênese, constituição e cotidiano do Grupo Escolar César Bastos, criado em Rio Verde - Goiás no ano de 1947, e sobre a relevância desta instituição de ensino, uma vez que a educação primária pública desta cidade se efetivava, até então, por meio do Grupo Escolar Eugênio Jardim, inaugurado em 1922.

Para tanto, parte-se da seguinte problemática: qual era o significado do grupo escolar no contexto histórico-educacional rio-verdense no período de 1947 a 1961 ? O recorte temporal ancora-se num projeto mais amplo de investigação, pois o ano de 1947 representa a criação da instituição a ser pesquisada e 1961, o ano em que foi promulgada a primeira Lei de Diretrizes e Bases da Educação Nacional: Lei 4024/61. 
Como se trata de uma pesquisa em andamento, o presente trabalho terá como diretriz, a análise da gênese do Grupo Escolar César Bastos e sua finalidade como instituição escolar no contexto histórico da cidade, sendo que, no plano específico, objetiva investigar aspectos que caracterizaram essa escola: sua implantação, o corpo docente e origem social dos alunos. Para tanto, a análise será considerada a partir do seu lugar de produção sócio-econômico, político e cultural, submetido a opressões, ligado a privilégios e enraizado em uma particularidade própria, conforme declara CERTEAU (1988).

O processo metodológico para a investigação, aqui proposta, inclui pesquisa bibliográfica, leitura e análise de dados estatísticos, catalogação e interpretação de documentos legais da escola, análise de fotografias, além de entrevistas orais com exprofessoras, ex-diretora e ex-alunos que vivenciaram o período em estudo, sempre considerando que:

\begin{abstract}
A história faz-se com documentos escritos, sem dúvida. Quando estes existem. Mas pode fazer-se, deve fazer-se sem documentos escritos, quando não existem. Com tudo o que a habilidade do historiador lhe permite utilizar para fabricar o seu mel, na falta das flores habituais. Logo, com palavras. Signos. Paisagens e telhas. Com as formas do campo e das ervas daninhas. Com os eclipses da lua e a atrelagem dos cavalos de tiro. Com os exames de pedras feitos pelos geólogos e com as análises de metais feitas pelos químicos. Numa palavra, com o que, pertencendo ao homem, exprime o homem, demonstra a presença. A atividade, os gostos e as maneiras de ser do homem. Toda uma parte, e sem dúvida a mais apaixonante do nosso trabalho de historiadores, não consistirá num esforço constante para fazer falar as coisas mudas, para fazê-las dizer o que elas por si próprias não dizem sobre os homens, sobre as sociedades que as produziram e para constituir, finalmente, entre elas, aquela vasta rede de solidariedade e de entreajuda que supre a ausência do documento escrito. (FEBVRE, 1949 apud LE GOFF, 2003, p. 530)
\end{abstract}

Como se trata de uma pesquisa cujo objeto de estudo seja uma instituição escolar, a metodologia versará sobre a análise da ata de instalação da escola, da legislação educacional, do currículo, da proposta pedagógica, do quadro de alunos e memórias. Como já mencionado, serão utilizados, para tanto, arquivos e fontes múltiplas (escritas, orais, imagens, sons e outras), considerando que “[...] o que dá o passaporte de ingresso (para as instituições escolares) é o conjunto de fontes que levanto, critico e seleciono, e nenhum tipo de fonte deve ser interditado" (SANFELICE, 2007, p. 77).

Para dar mais visibilidade às fontes relativas ao Grupo Escolar César Bastos, o quadro seguinte pretende sublinhar a importância e a relevância destes documentos para a pesquisa a respeito da história dessa instituição de ensino público primário.

Documentação do Grupo Escolar César Bastos depositada no Arquivo da Escola Estadual de Tempo Integral Cunha Bastos: 1947-1961

\begin{tabular}{|c|c|}
\hline Documentos & Possíveis investigações \\
\hline $\begin{array}{l}\text { 1. Ata da instalação da Escola } \\
\text { Popular de Rio Verde: } 1947\end{array}$ & $\begin{array}{l}\text { Apreensão e interpretação do processo de instalação do Grupo } \\
\text { Escolar: pessoas envolvidas, questões políticas e sociais. }\end{array}$ \\
\hline $\begin{array}{l}2 . \quad \text { Ata da eleição da Sociedade } \\
\text { Amigos da Instrução: } 1947\end{array}$ & $\begin{array}{l}\text { Identificação dos sujeitos que ocupavam os cargos de maior } \\
\text { destaque na Associação, assim como suas atribuições e posição } \\
\text { social na comunidade rio-verdense. }\end{array}$ \\
\hline Balancete da receita e despesas & Caracterização e interpretação dos investimentos realizados no \\
\hline
\end{tabular}




\begin{tabular}{l|l}
\hline $\begin{array}{l}\text { da Sociedade Amigos da Instrução: } \\
\text { 1947-1948 }\end{array}$ & Grupo Escolar, assim como principais financiadores. \\
\hline $\begin{array}{l}\text { 4. Livro do registro de ponto dos } \\
\text { funcionários: 1947-1961 }\end{array}$ & $\begin{array}{l}\text { Identificação dos funcionários do estabelecimento, número de } \\
\text { turmas atendidas e horário de funcionamento do Grupo Escolar. }\end{array}$ \\
\hline $\begin{array}{l}5 . \quad \text { Livros de Atas de Resultados } \\
\text { de Provas e Exames finais: 1953-1959 }\end{array}$ & $\begin{array}{l}\text { Identificação, análise e interpretação do tipo de avaliação } \\
\text { desenvolvida, número de aprovações e reprovações, questões } \\
\text { relacionadas ao currículo e ao gênero. }\end{array}$ \\
\hline $\begin{array}{l}\text { 6. Livro de Atas das festividades } \\
\text { escolares: 1959-1961 }\end{array}$ & $\begin{array}{l}\text { Identificação, análise e interpretação das principais festividades } \\
\text { realizadas pela escola, estabelecendo as principais datas e pessoas } \\
\text { lembradas e celebradas. }\end{array}$ \\
\hline 7. Ofícios: 1947-1953 & $\begin{array}{l}\text { Investigação, análise e interpretação das solicitações realizadas } \\
\text { pela diretora ao poder público local e ao secretário estadual da } \\
\text { educação, como também as possíveis respostas a essas. }\end{array}$ \\
\hline 8. & $\begin{array}{l}\text { Análise e interpretação das representações expressas por meio da } \\
\text { imagem. }\end{array}$ \\
\hline
\end{tabular}

Fonte: Elaborado pela autora com base nos documentos encontrados sobre o Grupo Escolar César Bastos, no Arquivo da Escola Estadual de Tempo Integral Cunha Bastos.

Valendo-se dessas e de outras fontes, compreender e explicar a realidade histórica do Grupo Escolar César Bastos significa "[...] integrá-la de forma interativa no quadro mais amplo do sistema educativo, nos contextos e nas circunstâncias históricas, implicando-a na evolução de uma comunidade e de uma região, seu território, seus público e zonas de influência". (MAGALHÃES, 2004, p. 133-134)

É o mesmo que se dizer que, no interior dessa instituição, há um quebra-cabeça a ser decifrado. Desse modo,

Uma vez dentro da instituição, trata-se de fazer o jogo das peças em busca dos seus respectivos lugares. Legislação, padrões disciplinares, conteúdos escolares, relações de poder, ordenamento do cotidiano, usos dos espaços, docentes, alunos e infinitas outras coisas ali se cruzam. Pode-se dizer que uma instituição escolar ou educativa é a síntese de múltiplas determinações, de variadíssimas instâncias (política, econômica, cultural, religiosa, da educação geral, moral, ideológica, etc.) que agem e interagem entre si, "acomodando-se" dialeticamente de maneira tal que daí resulte uma identidade. (SANFELICE, 2007, p. 77)

Assim, a apresentação parcial da montagem desse quebra-cabeça constitui a proposta de exposição deste trabalho. Dividida em duas partes: a primeira tem como objetivo contextualizar, por meio da legislação, o processo de implantação dos Grupos Escolares em Goiás e a segunda apresentará o município de Rio Verde, estabelecendo o lugar do Grupo Escolar César Bastos no contexto histórico-educacional da cidade.

\section{A implantação dos Grupos Escolares no Brasil e em Goiás}

A década de 1890, no âmbito político brasileiro, foi marcada pela centralidade dos debates em torno da educação, por meio do discurso influenciado pelas repercussões da Revolução Francesa, a qual apregoava a defesa da instrução elementar para todos, como forma de se obter a civilização. Desse modo, o projeto civilizador da nação, elaborado pelos republicanos, concebia a educação escolar - especialmente, o ensino primário como elemento propulsor da evolução da sociedade brasileira rumo aos avanços alcançados pelos países desenvolvidos. 
Um amplo projeto civilizador foi gestado, então, nessa época, e nele a educação popular foi ressaltada como necessidade política e social, uma vez que se fazia necessária a alfabetização dos cidadãos para sua participação política, o que tornava a instrução primária indispensável para a consolidação do regime republicano que ora emergia.

Nesse momento republicano houve um crescente movimento em defesa da instrução como via de integração do povo à nação e ao mercado de trabalho assalariado, que se viu fortalecido após a abolição da escravatura. Desse modo, houve a necessidade de "fundar a escola pública, uma vez que aquela que existia era identificada como atrasada e desorganizada". (FARIA FILHO, 2000, p. 30)

Os grupos escolares ou escolas graduadas surgiram, então, como promessa de progresso e superação de atraso, em oposição às precárias escolas do Império.

[...] carente de edifícios, livros didáticos e mobiliário, precária em pessoal docente qualificado para o ensino de crianças e distante dos modernos métodos pedagógicos. Nesse sentido, para a recém-instalada república brasileira, a experiência inovadora das escolas primárias graduadas- ou grupos escolares, como vieram a ser denominados - foi entendida como um investimento que contribuiria para a consolidação de uma intencionalidade que procurava, por sua vez, esquecer a experiência do Império e apresentar um novo tipo de educação que pretendia ser popular e universal. (BENCOSTTA, 2005, p. 69).

A implantação desse modelo de organização escolar teve início em São Paulo a partir de 1890, servindo de modelo aos demais estados. “[...] em São Paulo (1894), no Maranhão (1903), em Minas Gerais (1906), no Rio Grande do Norte (1908), em Mato Grosso (1908), no Espírito Santo (1908), na Paraíba (1911), em Santa Catarina (1911), em Sergipe (1916), em Goiás (1918)" (ARAÚJO, 2006, p. 236).

De acordo com o pronunciamento do então Presidente do Estado, João Alves Castro, até 1918 o ensino primário em Goiás não passava de uma fantasia.

Citando as leis promulgadas em 1911, 1913,1914 e 1916, com as quais se procurou remediar os males do ensino primário como obrigação dos municípios, leis que não tiveram execução, o presidente voltou a afirmar: "Tudo isso envolve a triste verdade de que o ensino primário em Goyaz é um mytho, não existe". (BRETAS, 1991, p. 504-505)

Para o presidente, a responsabilidade quanto à desorganização do ensino estava no "vaivém" das legislações, que ora colocavam a instrução primária a cargo das municipalidades, ora do governo estadual. Diante de tal constatação, João Alves de Castro, que já havia presenciado a situação do ensino primário enquanto Secretário da Instrução (1904-1907), resolve redigir um projeto de lei, organizando o ensino primário no estado. Em julho de 1918, o congresso goiano apreciou o texto oferecido pelo Presidente, aprovando-o , praticamente, sem discussões. Esse projeto se transformou na Lei $\mathrm{n}^{\circ} 631$, de 2 de agosto de 1918. O respectivo regulamento, também redigido pelo Presidente, foi aprovado e mandado executar pelo decreto $\mathrm{n}^{\circ} 5.930$, de 24 de outubro do mesmo ano. (BRETAS, 1991)

Esta nova lei traz, portanto, ao controle do Estado o funcionamento de todas as escolas, visto que obrigou as instituições municipais a seguirem as mesmas linhas das estaduais, visando assim à uniformidade do ensino. Sua grande novidade foi a introdução do grupo escolar, instituição que já era comum em outros estados da federação, como mencionado anteriormente. 
Sobre os Grupos Escolares, estipulou-se o seguinte:

Art. 21 - Além das escolas isoladas para ambos os sexos, serão creados, a juízo do Governo, Grupos Escolares nas cidades e villas de maior adeantamento ou naquellas em que a matrícula exceder a 300 alunos de ambos os sexos e com frequiência de 200 discente.

Art. 22 - Os Grupos Escolares poderão ser mixtos ou para cada sexo e funcionarão em predio especialmente construído para esse fim.

Art. 23 - Para a construção desses prédios ou de qualquer outro para escolas isoladas, o Governo entrará em acordo com os municípios, pagando estes a metade das despezas, de uma vez ou em quotas, adrede estipuladas.

Art. 24 - Fica creado desde já o Grupo Escolar da Capital, o qual substituirá o actual Curso Annexo à Escola Normal.” (BRETAS, 1991, p. 508)

A primeira cidade goiana a manifestar o desejo de possuir um grupo escolar foi Catalão, vizinha de Araguari e Uberlândia, de onde se recebia influência progressista. Todavia, não foi atendida de imediato, uma vez que nem mesmo a capital possuía um prédio público nos moldes solicitados, invejados das cidades mais desenvolvidas, por onde passavam lideranças políticas goianas em suas andanças. Era preciso esperar muito ainda.

O primeiro Grupo Escolar a instalar-se foi, como não poderia ser diferente, o da Capital, criado pela Lei 631. Logo após a sua instalação, alguns municípios começaram a pressionar o Governo em busca do mesmo benefício. Entre esses municípios reivindicadores, encontravam-se Rio Verde e, de maneira reincidente, Catalão.

Até o ano de 1928, o Estado de Goiás dispunha de dezesseis Grupos Escolares, assim distribuídos nos seguintes municípios: Campo Formoso (Orizona), Rio Verde, Ipameri, Pirenópolis, Jaraguá, Itaberaí, Goiás, Morrinhos, Bela Vista, Catalão, Trindade, Porto Nacional, Santa Riva do Paranaíba, Caiapônia, Anápolis e Jataí. (NEPOMUCENO, 1994).

A década de trinta representou, para Goiás, um período de democratização das oportunidades educacionais, que passaram a ser exigência tanto econômica quanto política, frente ao que vinha ocorrendo no território nacional, uma vez que:

O Brasil da década de trinta sofre modificações indicadoras de um incipiente processo de "modernização" econômica e social. Neste momento no país aparecem as marcas de uma urbanização vinculada com a industrialização atraindo pessoas para as cidades e no referente à cidadania, o Brasil tinha a obrigatoriedade da alfabetização para o ato de votar. (RIBEIRO; SILVA, 2009, p. 57).

Para tanto, fazia-se necessário expandir a instrução, principalmente o ensino primário, responsável pela alfabetização do povo goiano, ficando os Estados a cargo de tal função. Desse modo, o interventor do Estado, senhor Pedro Ludovico Teixeira - amigo pessoal do presidente - e demais líderes estaduais, diante do apelo de Getúlio Vargas, investiram profundamente na difusão do ensino primário, o que pode ser identificado na seguinte tabela: 


\begin{tabular}{l|l|l}
\hline 1929 & 16 & 161 \\
1930 & 20 & 161 \\
1933 & 26 & 261 \\
1935 & 31 & 182 \\
1936 & 38 & 152 \\
1939 & 46 & 145 \\
1940 & 45 & 145 \\
1941 & 47 & 149 \\
1942 & 49 & 155 \\
1945 & 74 & -- \\
\hline
\end{tabular}

Fonte: NEPOMUCENO (1994).

Mesmo com a implantação de tantos Grupos Escolares pelo interior do Estado de Goiás, Rio Verde só contava com o ensino público primário ministrado no Grupo Escolar Eugênio Jardim, criado em 1921. Em 1940, o município (incluindo os seus distritos), tinha uma população de 31.377 habitantes. Destes, 6.790 eram alfabetizados, isto é, 21,6\%. (BRASIL, 1952). Diante de um índice alto de analfabetismo: 78,4\%, a criação de outra escola pública primária fazia-se necessária. Emerge, neste contexto, a Escola Popular a qual mais tarde se tornaria o Grupo Escolar César Bastos.

\section{O lugar do Grupo Escolar César Bastos no contexto histórico-educacional de Rio Verde $^{2}(1947-1961)$}

No que tange aos aspectos educacionais, até 1856 não foram encontrados registros sobre a existência oficial de escola para instrução primária na Vila das Dores de Rio Verde. "A primeira escola primária de Rio Verde provavelmente foi criada em 1851, mas durante muito tempo o cargo ficou vago, já que não foi encontrado professor qualificado que o assumisse." MENDONÇA (2005, p. 138). Somente em 1876 é criada uma escola primária feminina, que dois anos depois é expandida aos dois sexos, devido à infrequência das alunas.

De 1876 a 1909 não são encontrados registros sobre a educação em Rio Verde. No entanto, as primeiras décadas do século $\mathrm{XX}$ são marcadas pela criação e extinção de estabelecimentos escolares, sendo estes, em sua quase totalidade, destinados ao ensino secundário, como pode ser observado no quadro abaixo.

Estabelecimentos escolares de Rio Verde entre os anos de 1910 e 1921

\begin{tabular}{|c|c|c|}
\hline Estabelecimento escolar & Ano de criação & Modalidade de ensino \\
\hline $\begin{array}{l}\text { Instituto de Sciências e Lettras } \\
\text { de Rio Verde }\end{array}$ & 1910 & Ensino secundário \\
\hline $\begin{array}{l}\text { Escola Municipal de Instrução } \\
\text { Primária* }\end{array}$ & 1911 & Ensino primário \\
\hline Colégio de Rômulo Franklin & 1914 & Ensino secundário \\
\hline Colégio João Pinheiro & 1917 & Ensino secundário \\
\hline Colégio São Vicente & 1920 & Ensino secundário \\
\hline $\begin{array}{lll}\text { Colégio Nossa } & \text { Senhora } & \text { da } \\
\text { Consolação } & & \\
\end{array}$ & 1921 & Ensino secundário \\
\hline Grupo Escolar Eugênio Jardim & 1921 & Ensino primário \\
\hline
\end{tabular}


Além da pouca importância atribuída ao ensino primário, percebe-se também o descaso do poder público perante as questões educacionais, o que não difere do restante do país, uma vez que:

[...] em termos de realizações concretas pouco se fez pelo ensino elementar nas primeiras décadas republicanas, embora em outras áreas como no ensino secundário e superior, e sobretudo no ensino pedagógico, técnico e profissional - tenha se observado um ligeiro desenvolvimento. (PAIVA 1987, p. 85)

A década de 40 representou um período de grande desenvolvimento para o município de Rio Verde. Nesse período, há a inauguração de uma nova hidrelétrica; as principais ruas da cidade recebem calçamento; é fundado o Aeroclube de Rio Verde; são instaladas as agências do Banco do Brasil, Banco do Comércio e Indústria de Minas Gerais e o Mercantil de Minas Gerais; o atual aeroporto é inaugurado. Mais uma vez, a educação não acompanhou o desenvolvimento, pois havia, como sempre houve, um contraste notável entre o poder econômico e a precariedade educacional, o que pode ser evidenciado nos $78,4 \%$ de analfabetos que possuía o município em tal período.

$\mathrm{Na}$ tentativa de suprir a carência das escolas públicas e amenizar a questão do analfabetismo, surgiu, na cidade, a Escola Popular de Rio Verde. Seu livro de registro informa que no dia 07/04/1947, sobre os olhares atentos de "diversas pessoas da sociedade local, amantes da instrução pública" $\left(\mathrm{GECB}^{3}\right.$. Ata de instalação da Escola Popular de Rio Verde: 1947), ocorreu o processo de fundação e instalação desta unidade escolar.

De acordo com a ata, a escola de instrução primária seria criada com o objetivo de "atender as necessidades das crianças menos favorecidas de recursos", ficando sob a responsabilidade da senhorita Rosilda Leão Guimarães, tendo como substituta, em caso de falta e impedimento, a senhora Carmem Cunha de Almeida e senhorita Ena Maria Ferreira. Os vencimentos das professoras - quinhentos cruzeiros mensais - ficariam a cargo do senhor César da Cunha Bastos ${ }^{4}$.

$\mathrm{Na}$ ata de fundação da unidade escolar, ficou acordado que, em oportunidade futura criaria-se uma sociedade de fins filantrópicos e educacionais, regida por um estatuto, com o objetivo de constituir-se em pessoa jurídica. E mediante essas decisões, formou-se uma comissão para a elaboração do estatuto, composta pelo senhor Solon da Cunha Bastos, Jesuíno de Souza Gomes e Ena Maria Ferreira.

Encerrando a cessão de criação e instalação da escola, o senhor César da Cunha Bastos, expondo a todos da finalidade da escola ${ }^{5}$, fez questão de ressaltar que tal obra não tinha objetivos políticos, enaltecendo, no momento, o empenho das professoras e, destacando o respeito que merece aqueles que ministram a instrução. Tal ênfase dada ao trabalho das professoras remonta-nos ao final do século XIX, em que:

A importância dada à educação popular nesse período propiciou a constituição de representações sobre a profissão docente nas quais o professor passou a ser responsabilizado pela formação do povo, o elemento reformador da sociedade, o portador de uma nobre missão cívica e patriótica. (SOUZA, 1998, p. 60)

Instalada a escola, foi criado o Estatuto, onde estabelecia que, a sociedade civil de fins sociais e educacionais receberia o nome de "Sociedade Amigos da Instrução", tendo como objetivo: 
a) Colaborar com os poderes públicos e, particularmente, com a Prefeitura Municipal, no sentido de promover o mais eficientemente possível em todo o Município, a difusão da Instrução, como preceitua a Constituição da República.

b) Promover festivaes e angariar donativos para a aquisição de livros escolares e demais material a ser fornecido gratutitamente às creanças menos favorecidas. (GECB. Ata da eleição da diretoria da Sociedade Amigos da Instrução: 1947)

Com relação aos sócios, estes seriam organizados em função da colaboração que exerceriam. Àqueles que prestassem serviço de grande vulto ou contribuíssem com um valor superior a quinhentos cruzeiros receberiam homenagem especial, com direito a proclamação nas sessões. Seriam considerados sócios fundadores todos os que subscreveram a ata da instalação da Escola Popular de Rio Verde.

A administração seria composta por meio de uma diretoria, formada por pessoas de ambos os sexos, eleitas anualmente, por escrutínio secreto. Fariam parte da diretoria o presidente, vice-presidente, primeiro e segundo secretários, tesoureiro e corpo técnico ${ }^{6}$. À sociedade, caberia o direito de criar escolas onde julgasse necessário. O presidente ficaria responsável pela superintendência de todos os serviços da Associação, autorização das despesas, e desígnios de pessoas para determinados trabalhos. O vice-presidente auxiliaria e substituiria o presidente em caso de impedimento. Ao primeiro secretário, caberia a função de cuidar das correspondências e do bom andamento da Associação. Redigir as atas durante as sessões seria a função do segundo secretário. O tesoureiro cuidaria da guarda do dinheiro, receberia as contribuições e donativos e faria a movimentação financeira da Sociedade, prestando conta à diretoria. Não foram definidas as funções do corpo técnico.

No que tange ao patrimônio, o Art. $9^{\circ}$ do Estatuto estabelece o seguinte:

A Sociedade organizará seu patrimônio, observados os princípios de economia, com os seguintes elementos:

a) Subvenção do Estado e da União;

b) Subvenção da Prefeitura Municipal;

c) Contribuição dos sócios;

d) Donativos;

e) Produtos de festivaes;

f) Eventuaes.

$\S$ Único - A sociedade empreenderá serviços dentro de suas possibilidades orçamentárias, cujas estimativas caberão aos órgãos deliberativos $^{7}$, que as coordenarão. (GECB. Estatuto da Sociedade Amigos da Instrução: 1947)

Ficou evidente, portanto, que se tratou de uma instituição privada, que, em nome da liberdade de ensino, buscaria financiamento do poder público municipal e estadual. Tal atitude, posteriormente - em 1958 - viria à discussão no substitutivo que pretendeu deslocar, na Câmara Federal, o projeto da Comissão de Educação e Cultura sobre Diretrizes e Bases da Educação Nacional, ao apresentar como um de seus princípios, que caberia ao Estado subvencionar, financeiramente, as escolas privadas. (BARROS, 1960, p. 22)

Em caso de dissolução da Sociedade, seu patrimônio seria revertido à Prefeitura Municipal, sendo representada ativa e passivamente, judicial e extrajudicialmente pelo seu presidente, senhor César da Cunha Bastos, eleito junto a toda diretoria logo após a apresentação do Estatuto, ficando assim estabelecida: presidente: César da Cunha Bastos, 
vice-presidente: Jerônimo Ribeiro de Macedo, secretária: Ena Maria Ferreira, tesoureiro: Jesuíno de Souza Gomes.

No dia 12 de setembro de 1948, às nove horas, teve início a solenidade de instalação da Escola Popular em seu prédio próprio. Na ocasião, estiveram presentes lideranças políticas, civis e militares.

Previamente convidados pelo Exm. Sr. Dr. César da Cunha Bastos, muito digno presidente da Associação Amigos da Instrução, compareceram como convidados de honra, o Ex. Dr. Governador do Estado, e ainda o deputado Wilmar Guimarães,acompanhado de sua Exma. esposa. Deputados Dr. José Hercílio Fleury , Dr. Urquiza Fleury de Brito, Domingos Jacinto Pinheiro e o Promotor da Capital de Goiaz Dr. Lúcio Arantes, autoridades civis, eclesiásticas e militares, diretores dos diversos estabelecimentos de ensino, professores, instrutor e pracinhas do T.G. 56 e demais pessoas gradas. (GECB. Ata Inaugural: 1948).

Dentre as lideranças políticas mencionadas, nenhuma pertencia ao município. O então governador do Estado, senhor Jerônymo Coimbra Bueno, natural de Rio Verde, venceu as eleições tendo como base uma coligação que incluía a UDN - partido político representado por César da Cunha Bastos em Rio Verde - o PSP e uma dissidência do PSD, fazendo assim oposição à política rio-verdense. A presença de autoridades estaduais se justifica pelo fato de que:

O bem e o mal, que os chefes locais estão em condições de fazer aos seis jurisdicionados, não poderiam assumir as proporções habituais sem o apoio da dituação política estadual para uma e outra coisa. Em primeiro lugar, grande cópia de favores pessoais depende fundamentalmente, quando não exclusivamente, das autoridades estaduais. (LEAL, 1997, p. 64-65)

Após o corte da fita simbólica, ocorreu a sessão discurso, sendo de início proferido pelo então presidente da Associação, Dr. César da Cunha Bastos, que, em "expressões patrióticas e cheias de entusiasmo em prol do melhoramento educacional de nossa turma discursou, sendo bastante ovacionado" (GECB. Ata inaugural: 1948). Prosseguindo, o deputado Wilmar Guimarães, representando o Secretário da Educação do Estado, regozijou-se com seus conterrâneos diante de tão memorável feito. Dando continuidade, a senhorita Ena Maria Ferreira, então nomeada diretora da escola recém-inaugurada, realiza um discurso em homenagem a César Bastos, propondo um nome para o Grupo Escolar.

Ena Maria Ferreira, nomeada diretora da escola recém-inaugurada, que numa belíssima oração, muito promete em prestar sua brilhante cultura e grande atividade para o progresso do ensino, nesta parte do hiterlândio brasileiro. Falou em torno da pessoa dinâmica do Dr. César da Cunha Bastos que muito trabalhou para a concretização dessa grande obra, pois segundo disse Vitor Hugo: "abrir escolar é fechar cadeias", propoz, segundo, digo, ainda que em tributo a tão grandes obras, recebesse a escola a denominação de Grupo Escolar César Bastos. (GECB. Ata Inaugural: 1948).

Como se vê, tal escolha foi feita com o objetivo de engrandecer o nome do presidente da Associação, senhor César da Cunha Bastos, e de imortalizá-lo na memória 
dos rio-verdenses. Condição esta que já vinha ocorrendo no Brasil desde 1912, em relação à nominação dos grupos escolares.

Inicialmente, eles eram identificados como sendo o Primeiro $\left(1^{\circ}\right)$, o Segundo $\left(2^{\circ}\right)$ ou o Terceiro $\left(3^{\circ}\right)$ Grupos Escolares da capital. No entanto, a partir de 1912, mudou-se essa sistemática, passando-se a identificar os grupos escolares, novos ou já organizados, pelo nome de personalidades cujos nomes e feitos queria-se "imortalizar" na memória da cidade. (FARIA FILHO, 2000, p. 49-50)

Finalizando, o governador do Estado, Jerônymo Coimbra Bueno, afirma que tal marco épico levaria Rio Verde à senda do progresso. Após o batismo do grupo escolar, realizado pelo padre Ângelo Gosgaya, a população é convidada a visitar as dependências da escola recém-inaugurada, composta de quatro salas de aula, sala da diretora e banheiros masculino e feminino. Instalada longe do centro, na parte alta da cidade, a arquitetura do prédio não correspondia ao palácio do primeiro grupo escolar, uma vez que:

O lugar da educação escolar no centro da cidade - lugar dos palácios não é o mesmo que nos subúrbios - lugar dos pardieiros. Assim, os typos para construção dos grupos escolares ressaltavam a singularidade do local onde deveriam ser construídos[...]. (FARIA FILHO, 2000, p. 39)

Criado para atender a crianças menos favorecidas financeiramente, é possível perceber, por meio de entrevistas realizadas com ex-professoras, que o Grupo Escolar César Bastos acolhia a um considerável número de crianças denominadas pobres, porém, atendia também a alunos com condições financeiras mais favoráveis, como filhos de fazendeiros. Quando questionada sobre a origem social dos alunos, dona Gélcia ressalta:

Classe média, para baixa. Mais pra baixa. Classe social alta era algum. Tem o José Carlos, que hoje é secretário da prefeitura, funcionário lá que era aluno nosso. Ele era da classe mais alta um pouquinho, sabe!? Tinha muito pouquinho aluno com classe mais alta. Nosso mesmo era classe média pra baixo. Era bem em cima, né!? Então era classe mais baixa. [...]. Lá tinha também muitos filhos de fazendeiro, porque era mais no alto e geralmente moravam mais no alto também, né!? Então vinha gente demais de fazenda. (SILVA, 2012)

No que diz respeito ao corpo docente, este, até o ano de 1961, era formado quase que exclusivamente por mulheres, ocorrendo apenas a presença de um professor substituto no ano de 1952. (GECB. Livro de pontos: 1947 a 1961). Tal situação não difere do que vinha ocorrendo em todo o Brasil, durante as primeiras décadas do século XX, em que o magistério representou praticamente a única carreira aberta às mulheres. "Para as professoras primárias da primeira metade do século XX, o magistério foi o ponto de partida, foi o possível no momento histórico em que viveram" (ALMEIDA, 2004, p. 81).

Considerando o particular como expressão do desenvolvimento geral, pode-se afirmar, pelo exposto até o momento, que a singularidade do Grupo Escolar César Bastos, ao constituir-se amostra significativa do que aconteceu no resto do país, contribuiu para a compreensão do processo educacional em seu contexto mais amplo.

\section{Considerações finais}


Diante do exposto, o que se pode concluir, mesmo que parcialmente, é que questões políticas - reverberaram tanto com as rivalidades locais quanto com as de âmbito nacional - permearam todo o processo de criação e implantação do Grupo Escolar César Bastos, uma vez que a referida instituição surgiu do interesse particular de um político rioverdense que, com ajuda dos amigos, conseguiu edificar o segundo Grupo Escolar de Rio Verde, buscando conservar sua posição de liderança com essa realização de utilidade pública.

Além do mais, a instituição escolar teve papel expressivo no cenário educacional rio-verdense, contribuindo para a diminuição do índice de analfabetismo, que se encontrava no percentual de $78,4 \%$, em 1940, década de sua criação. Para tanto, naquele momento, era necessária a criação de uma segunda escola pública, pois existia, no cenário rio-verdense, apenas um grupo escolar.

Diante das fontes localizadas dessa instituição escolar, pode-se afirmar que a pesquisa tem proporcionado o desvelamento a respeito da situação da escola pública instituída no município no período histórico selecionado, em especial do Grupo Escolar César Bastos, ampliando o corpus de conhecimento sobre a história da educação de Goiás, até então parca de investigação.

\section{Referências}

ALMEIDA, Jane Soares de. Mulheres na educação: missão, vocação e destino? A feminização do magistério ao longo do século XX. . In. SAVIANI, Dermeval (Org) O legado educacional do século XX no Brasil. Campinas, SP: Autores Associados, 2004.

ARAÚJO, José Carlos Souza. Os grupos escolares em Minas Gerais como expressão de uma política pública: uma perspectiva histórica. In: Grupos Escolares: cultura escolar primária e escolarização da infância no Brasil (1893-1971). Campinas: Mercado das Letras, 2006.

BARROS, Roque Spencer Maciel de. Diretrizes e bases da educação nacional. São Paulo: Pioneira, 1960.

BENCOSTTA, Marcos Levy Albino. Grupos escolares no Brasil: um novo modelo de escola primária. In: Histórias e memórias da educação no Brasil, Vol. III - Século XX. Rio de Janeiro: Vozes, 2005.

BORGES, Filadelfo. César Bastos: vida e obra. Goiânia: Gráfica e Editora O popular, 1987.

BRASIL. Instituto Brasileiro de Geografia e Estatística. Censo Demográfico do Estado de Goiaz. Série regional. Volume XXI. Rio de Janeiro, 1952.

BRETAS, Genesco. História da instrução pública em Goiás. Goiânia: CEGRAF/UFG, 1991.

CERTEAU, Michel. A operação histórica. In. LE GOFF, Jacques; NORA, Pierre. (Dir.) História: novos problemas. 2 ed. Rio de Janeiro: Francisco Alves, 1988. 
CUNHA NETO, Oscar. Rio Verde: apontamentos para a sua história. Goiânia: Gráfica e Editora O popular, 1988.

FARIA FILHO, Luciano Mendes de. Dos pardieiros aos palácios: cultura escolar e urbana em Belo Horizonte na Primeira República. Passo Fundo: UPF, 2000.

FAUSTO, B. A Revolução de 1930: historiografia e história. 12. Ed.São Paulo: Brasiliense, 1985.

LEAL, Victor Nunes. Coronelismo, enxada e voto. 3 ed. Rio de Janeiro: Nova Fronteira, 1997.

LE GOFF, Jacques. Documento/Monumento. In. LE GOFF, Jacques. História e memória. Trad. Bernardo Leitão [ET AL.]. - 5 ed. - Campinas, SP: Editora da UNICAMP, 2003.

MAGAlHÃES, Justino. Tecendo Nexos: História das instituições educativas. Bragança Paulista: Editora Universitária São Francisco, 2004.

MENDONÇA, Zilda Gonçalves de Carvalho. A história da formação docente: a singularidade da Escola Normal de Rio Verde, GO (1933-1974). Goiânia: Asa, 2005.

NEPOMUCENO, Maria de Araújo. A ilusão pedagógica (1930-1945): estado, sociedade e educação em Goiás. Goiânia: Editora da UFG, 1994.

RIBEIRO, Betânia de Oliveira Laterza; SILVA, Elizabeth Farias de. O Grupo Escolar de Villa Platina e a educação: variações intrínsecas sobre um prédio determinado. In: SOUZA, Sauloéber Társio de; RIBEIRO, Betânia de Oliveira Laterza (orgs.). Do público ao privado, do confessional ao laico: a história das instituições escolares na Ituiutaba do século XX. Uberlândia (MG): Edufu, 2009.

SANFELICE, J. L. História das instituições escolares. In: Novos temas em História da Educação Brasileira. In: ARAÚJO, José Carlos Souza; GATTI JR., Décio (Org.) . Novos temas em História da Educação Brasileira: instituições escolares e educação na imprensa. Campinas, SP: Autores Associados; Uberlândia, EDUFU, 2007.

SOUZA, Rosa Fátima de. Templos de civilização: a implantação da escola primária graduada no estado de São Paulo: (1890-1910). São Paulo: Fundação Editora da UNESP, 1998.

PAIVA, Vanilda Pereira. Educação Popular e educação de adultos. 5 ed. São Paulo: Loyola, 1987.

\section{MATERIAIS HISTÓRICOS}

GECB. Ata da instalação da Escola Popular de Rio Verde: 1947 Ata da eleição da Sociedade Amigos da Instrução: 1947 Livro do registro de ponto dos funcionários: 1947-1961

\section{FONTE ORAL}


SILVA, Gelcia Maria. Entrevista concedida em 24/08/12. (60 min). Nasceu no dia 02/03/1929. Estudou na Escola Normal Rural de Rio Verde e FESURV: Universidade de Rio Verde. Foi diretora do Grupo Escolar César Bastos, iniciando seu mandato em 1951.

\section{Notas}

${ }^{1}$ Trabalho apresentado no VII Congresso Brasileiro de História da Educação: Circuito e Fronteiras da História da Educação no Brasil.

2 Rio Verde é uma cidade localizada no sudoeste goiano, distante em $220 \mathrm{Km}$ de Goiânia, a capital do Estado de Goiás. Com 158 anos de fundação, possui hoje cerca de 185.465 habitantes - sendo o quarto município com maior número de habitantes do Estado . Tem sua economia pautada na agricultura e pecuária, dispondo de uma estrutura agro-industrial referência no Brasil.

${ }^{3}$ Grupo Escolar César Bastos.

4 César da Cunha Bastos nasceu no dia 28 de novembro de 1898. Seu pai, Luiz da Cunha Bastos, além de proprietário de terras, era coletor estadual, estabelecendo ligações políticas com o sistema dominante caiadista, que governava Goiás. Em 1925, se torna bacharel em Direito. Pelo prestígio político do pai, foi nomeado Promotor Público de Rio Verde, deixando o cargo para tornar-se Juíz de Direito da Comarca. Após dois meses exercendo a função, recebe do governo Ramos Caiado (1929) a proposta para ser Secretário do Interior, Justiça, Educação e Saúde, a qual aceita de imediato, implantando o primeiro Jardim de Infância do Estado, bem como o primeiro Grupo Escolar de Jataí. Com o Movimento de 30, tem seu mandato de Deputado Federal interrompido. Durante todo o governo de Getúlio Vargas manteve-se na oposição. Em 1947, com o apoio da UDN e PSP, Jerônymo Coimbra Bueno assume o governo do Estado e, após um período do seu mandado, convida César da Cunha Bastos a assumir a Secretaria da Fazenda do Estado. Participando de alguns processos eleitorais futuros, vê frustradas as tentativas tanto para Deputado Federal (1954, 1962, 1970, 1974) quanto para governador do Estado (1958). Em 1973 doa o terreno para a construção da FEURV - primeira instituição do ensino superior de Rio Verde. A pedido do prefeito, César da Cunha Bastos exerce o cargo de diretor - presidente da instituição. Faleceu em 1992, tendo poucas pessoas em seu sepultamento. (BORGES, 1987)

${ }^{5} \mathrm{O}$ documento não menciona quais eram as finalidades.

${ }^{6}$ Comporiam o corpo técnico as professoras normalistas ou professoras.

${ }^{7}$ A Diretoria e o Corpo Técnico constituiriam o órgão deliberativo. 